\title{
Análise do NVDI em uma área de transição de cerrado e vegetação secundária no município de Vigia-Pará-Brasil
}

NVDI analysis in a transition area of cerrado and secondary vegetation in the municipality of

Vigia-Pará-Brasil

Análisis NVDI en un área de transición de cerrado y vegetación secundaria en el municipio de

Vigia-Pará-Brasil

Márciá Nazaré Rodrigues Barros

ORCID: https://orcid.org/0000-0003-0495-3995 Universidade Federal do Pará, Brasil E-mail: mnrbarros@gmail.com

Veríssimo César Sousa da Silva

ORCID: https://orcid.org/0000-0003-0539-315X Universidade Federal do Pará, Brasil

E-mail: verissimo_cesar@yahoo.com.br

Lucyana Barros Santos

ORCID: https://orcid.org/0000-0001-9584-9274 Secretaria de Estado de Meio Ambiente e Sustentabilidade, Brasil E-mail: lucyana_barros@hotmail.com

Aline Meiguins

ORCID: https://orcid.org/0000-0002-0594-0187 Universidade Federal do Pará, Brasil E-mail: alinemeiguins@gmail.com

Marcos Adami

ORCID: https://orcid.org/0000-0003-4247-4477

Instituto Nacional de Pesquisas Espaciais, Brasil E-mail: marcos.adami@inpe.br

Francimary da Silva Carneiro

ORCID: https://orcid.org/0000-0002-1693-8779 Secretaria de Estado de Meio Ambiente e Sustentabilidade, Brasil

E-mail: francimarycarneiro@gmail.com

Simone Aparecida Almeida Araújo

ORCID: https://orcid.org/0000-0001-5402-0080 Instituto Federal de Educação Ciência e Tecnologia do Pará, Brasil E-mail: simonearaujo.vet@gmail.com

Klewton Adriano Oliveira Pinheiro

ORCID: https://orcid.org/0000-0003-2696-4249 Instituto Federal de Educação, Ciência e Tecnologia do Pará, Brasil E-mail: klewton.pinheiro@gmail.com

Marcio Braga Amorim

ORCID: https://orcid.org/0000-0001-7508-2766 Secretaria de Estado de Meio Ambiente e Sustentabilidade, Brasil E-mail: marciobamorim@gmail.com

\begin{abstract}
Resumo
Este trabalho objetivou analisar as mudanças de uso e cobertura vegetal do município de Vigia e avaliar o Índice de Vegetação da Diferença Normalizada-NDVI em uma área de transição de cerrado e vegetação secundária no mesmo município. Apresentando duas escalas diferentes, uma a nível municipal e a outra análise foi a nível local. A classe Pastagem apresentou aumento, passando de $107 \mathrm{~km}^{2} \mathrm{em} 1985$ para $108 \mathrm{Km}^{2} \mathrm{em}$ 2018, perdendo área para as classes Urbana e Vegetação Secundária, $9,85 \mathrm{~km}^{2}$ e $60,43 \mathrm{Km}^{2}$, respectivamente. A Classe de Vegetação Secundária apresentou um aumento de 32,92 $\mathrm{Km}^{2}$, passando de 161,13 $\mathrm{Km}^{2}$ em 1985 para 194,05 $\mathrm{Km}^{2}$ em 2018 , sendo a principal contribuição da classe de pastagem com $60,43 \mathrm{Km}^{2}$. A classe de Cerrado apresentou uma diminuição expressiva, no ano de 1985 o município de Vigia apresentava $9,85 \mathrm{~km}^{2}$, diminuindo para $4042 \mathrm{~km}^{2}$ no ano de 2018 , perda de 5,42 $\mathrm{Km}^{2}$ de área de Cerrado, perdendo para classes de urbano, pastagem e vegetação secundária. Concluindo que o monitoramento de uso e cobertura das da terra torna-se importante para as áreas consideradas de não floresta como o Cerrado, principalmente no bioma Amazônia, pelas características peculiares de transição entre Cerrado e outros tipos de vegetação, pois com o monitoramento é possível detectar degradações e desmatamento,
\end{abstract}


contribuindo dessa forma para a gestão de políticas públicas voltadas para a preservação da biodiversidade dessas áreas.

Palavras-chave: Índice de vegetação; Google Earth engine; Monitoramento; Geotecnologia.

\begin{abstract}
This study aimed to analyze the changes in use and vegetation cover in the municipality of Vigia and to evaluate the Normalized Difference Vegetation Index-NDVI in a transition area of cerrado and secondary vegetation in the same municipality. Presenting two different scales, one at the municipal level and the other analysis was at the local level. The Grassland class showed an increase, from $107 \mathrm{~km}^{2}$ in 1985 to $108 \mathrm{~km}^{2}$ in 2018, losing area to the Urban and Secondary Vegetation classes, $9.85 \mathrm{~km}^{2}$ and $60.43 \mathrm{~km}^{2}$, respectively. The Secondary Vegetation Class showed an increase of $32.92 \mathrm{~km}^{2}$, from $161.13 \mathrm{~km}^{2}$ in 1985 to $194.05 \mathrm{~km}^{2}$ in 2018 , with the main contribution of the pasture class with $60.43 \mathrm{~km}^{2}$. The Cerrado class showed a significant decrease, in 1985 the municipality of Vigia had $9.85 \mathrm{~km}^{2}$, decreasing to $4042 \mathrm{~km}^{2}$ in 2018 , loss of $5.42 \mathrm{~km}^{2}$ of Cerrado area, losing to urban classes, pasture and secondary vegetation. Concluding that the monitoring of land use and land cover becomes important for areas considered to be non-forest like the Cerrado, especially in the Amazon biome, due to the peculiar characteristics of transition between Cerrado and other types of vegetation, because with monitoring it is possible detect degradation and deforestation, thus contributing to the management of public policies aimed at preserving the biodiversity of these areas.
\end{abstract}

Keywords: Vegetation index; Google Earth engine; Monitoring; Geotechnology.

\title{
Resumen
}

Este estudio tuvo como objetivo analizar los cambios de uso y cobertura vegetal en el municipio de Vigía y evaluar el Índice de Vegetación de Diferencia Normalizada-NDVI en un área de transición de cerrado y vegetación secundaria en el mismo municipio. Presentando dos escalas diferentes, una a nivel municipal y el otro análisis fue a nivel local. La clase Pastizal mostró un incremento, de $107 \mathrm{~km}^{2}$ en 1985 a $108 \mathrm{~km}^{2}$ en 2018, perdiendo área frente a las clases Urbana y Vegetación Secundaria, $9,85 \mathrm{~km}^{2}$ y $60,43 \mathrm{~km}^{2}$, respectivamente. La Clase Vegetación Secundaria mostró un incremento de 32,92 km², pasando de $161,13 \mathrm{~km}^{2}$ en 1985 a 194,05 km $\mathrm{km}^{2}$ en 2018, con el principal aporte de la clase pastos con $60,43 \mathrm{~km}^{2}$. La clase Cerrado mostró una disminución significativa, en 1985 el municipio de Vigia tenía $9,85 \mathrm{~km}^{2}$, disminuyendo a $4042 \mathrm{~km}^{2}$ en 2018 , pérdida de $5,42 \mathrm{~km}^{2}$ del área de Cerrado, perdiendo clases urbanas, pastos y vegetación secundaria. Concluyendo que el monitoreo del uso del suelo y la cobertura del suelo se vuelve importante para las áreas consideradas no forestales como el Cerrado, especialmente en el bioma amazónico, debido a las peculiares características de transición entre el Cerrado y otros tipos de vegetación, porque con el monitoreo es posible detectar la degradación y la deforestación, contribuyendo así a la gestión de políticas públicas encaminadas a preservar la biodiversidad de estas áreas.

Palabras clave: Índice de vegetación; Motor de Google Earth; Supervisión; Geotecnología.

\section{Introdução}

A Amazônia é o maior ecossistema florestal tropical contínuo na Terra, sua importância ecológica se expressa na grande diversidade de espécies vegetais, no entanto, apesar de ser composto por grandes extensões florestais também apresenta formações vegetais não florestais, que se estendem por 290 mil quilômetros quadrados do Bioma, e é composta principalmente por campinaranas e savanas (IBGE, 2012), que ocorrem como ilhas cercadas por formações florestais, e se caracterizam por serem habitats ímpares e extremamente frágeis no que se refere às interferências antropogênicas (Primack 2001, Begon 2005, Magurran 2011, Ricklefs 2011, PBMC, 2016). O estado do Pará é o estado que apresenta a maior área desmatada da Amazônia com $262.088 \mathrm{~km}^{2}$, o que equivale a 33,72\% do total desmatado até o ano de 2016 (INPE, 2017).

As Florestas secundárias, regionalmente conhecidas como capoeiras, estão diretamente integradas ao sistema de produção denominado pousio, contribuem para diversos serviços ambientais, como a remoção de carbono atmosférico que auxilia para atenuar as emissões de gases de efeito estufa para atmosfera, além de estabelecer a conectividade ente os remanescentes florestais como efeito positivo na manutenção da biodiversidade (Vieira \& Gardner, 2012).

Segundo Ferreira et al. (2012), as formações não florestais na Amazônia possuem grande importância para a conservação da biodiversidade, como as campinaranas que se caracterizam pela presença de espécies raras e muitas vezes endêmicas (MMA, 2013).

Segundo Gardner et al. (2013), as mudanças de uso e cobertura da terra contínuas são impulsionadas pelo aumento das demandas de recursos da população aliada aos efeitos do aumento da globalização econômica e escassez de terra. Além 
disto, ocasiona a fragmentação da paisagem afetando a biodiversidade e as funções ecossistêmicas. Considerado o sensoriamento remoto imprescindível para a interpretação e classificação da dinâmica da paisagem de uma determinada região, bem como, uma ferramenta importante na extração de informações de áreas de difícil acesso como apoio à gestão do território, o mapeamento do uso da terra e da vegetação natural pode subsidiar ações que visam ao estabelecimento de práticas de desenvolvimento sustentável e à implementação de políticas de conservação e uso sustentável da biodiversidade (Abreu \& Coutinho, 2014).

A plataforma Google Earth Engine de processamento geoespacial é baseada em nuvem para análise de dados ambientais, com o objetivo de realizar o desenvolvimento de algoritmos altamente interativos em escala global. Apresenta como principais componentes um conjunto de dados em escala de pentabytes de imagens de sensoriamento remoto disponíveis publicamente, infraestrutura computacional que otimiza o processamento paralelo dos dados geoespaciais, interface de programação de aplicativos para JavaScript e Python e editor de códigos para prototipagem rápida e visualização de análises espaciais complexas usando JavaScript (Google Earth Engine, 2018).

A partir do conhecimento adquirido na plataforma Google Earth Engine será possível realizar o mapeamento de uso e cobertura da terra e dessa forma contribuir para o monitoramento das áreas de cobertura natural como as áreas de cerrado no Bioma Amazônia, a fim de entender a dinâmica de interação dessas áreas. Por isso este trabalho objetivou analisar as mudanças de uso e cobertura vegetal do município de Vigia e avaliar o Índice de Vegetação da Diferença Normalizada-NDVI em uma área de transição de cerrado e vegetação secundária no mesmo município.

\section{Metodologia}

\section{Área de estudo}

O município de Vigia está localizado na mesorregião Nordeste Paraense,na microrregião do Salgado, na coordenada geográfica $00^{\circ} 51^{\prime} 33 " \mathrm{~S}$ e $48^{\circ}$ 08'28"W (Figura 1), com área total de 401,589 $\mathrm{Km}^{2}$, , distante aproximadamente a $77 \mathrm{~km}$ de Belém - a capital do Estado - limita-se a oeste pela ilha de Colares, ao sul pelos Municípios de Castanhal e Santo Antônio do Tauá, a leste pelo Município de São Caetano de Odivelas e ao norte pelo Oceano Atlântico (IBGE, 2017). O clima é o equatorial do tipo Af, segundo a classificação de Köppen. Apresenta temperatura média de $27^{\circ} \mathrm{C}$, sendo dezembro o mês mais quente. A amplitude térmica é mínima e o clima é amenizado pela proximidade do oceano. A precipitação pluviométrica é relativamente elevada, com cerca de $2.770 \mathrm{~mm}$. Os primeiros seis meses do ano são os mais chuvosos e nos meses de setembro e outubro há uma pequena estiagem. Quanto a disponibilidade de água no solo, o excedente está entre os meses de fevereiro e março, sendo que os de maior deficiência são os meses de setembro e outubro. A cobertura vegetal original de terra firme, composta pelo subtipo floresta densa dos baixos platôs, pela ação dos desmatamentos foi substituída pela Floresta Secundária, atingindo estas, vários estágios de regeneração. Nas planícies aluviais (sujeitas a inundação), onde não existe a influencia salina do mar, ocorrem florestas de várzea e as matas ciliares. Nas proximidades das embocaduras dos rios e no litoral predominam os manguezais, No Município estão presentes manchas de Latossolo Amarelo distrófico, textura média, e Gley Pouco Úmido distrófico, textura argilosa. Também, há presença do Podzol Hidromórfico e do Latossolo Amarelo dstrófico, textura média. Os valores altímetros medianos são inexpressivos, uma vez que o município está localizado, praticamente, ao nível do mar, com a sede municipal apresentando valores em torno de $6 \mathrm{M}$, havendo pequenos acréscimos de cotas mais para o sul de seu território. ( Sepof, 2018; Ramos, 2007, Idesp, 2012, Silva 2018)). 
Figura 1. Localização da área de estudo.

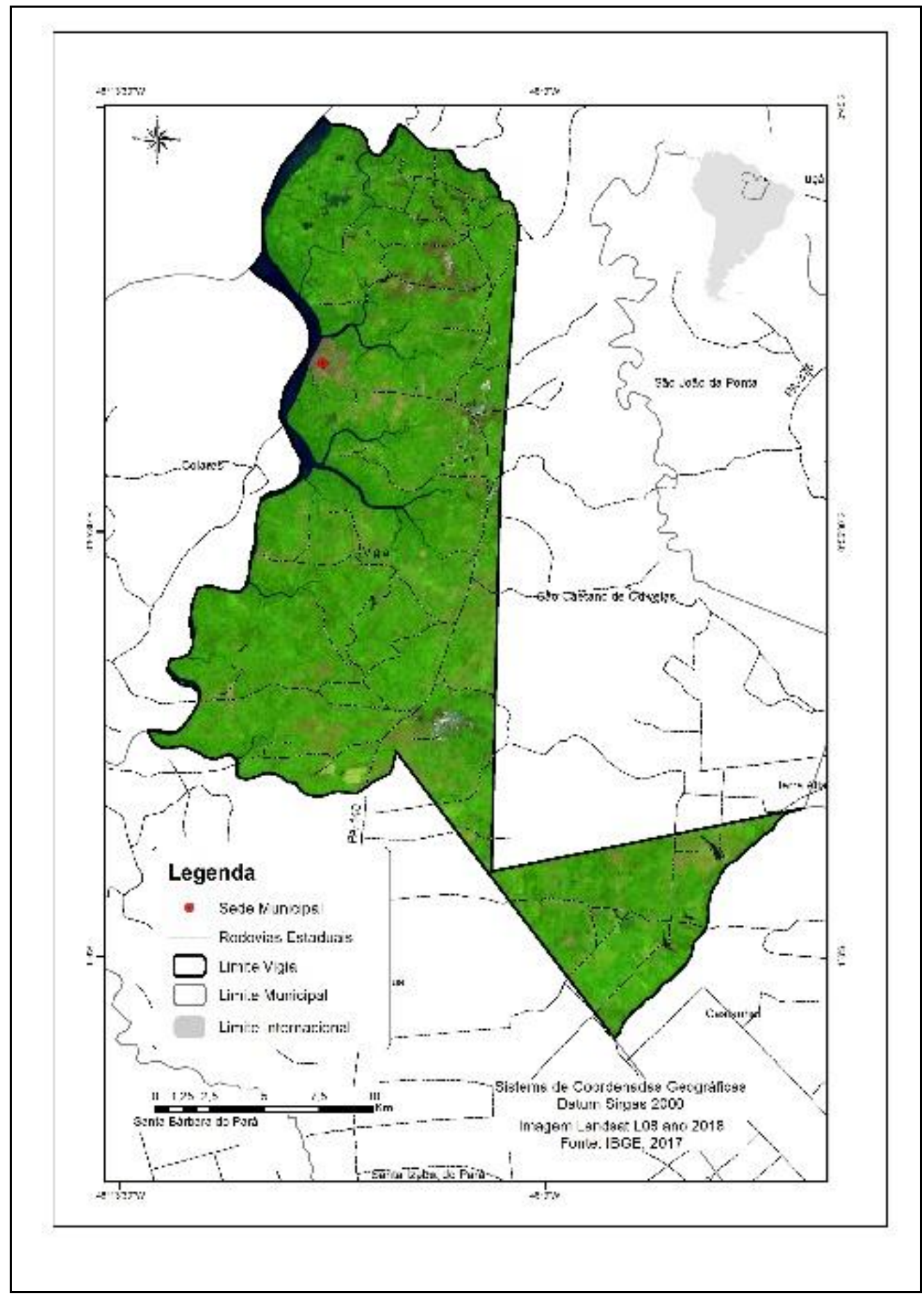

Fonte: Autores.

Este estudo apresentou duas escalas diferentes, uma a nível municipal com objetivo de analisar as mudanças de uso e cobertura do município de Vigia e a outra análise foi a nível local, onde realizou-se uma caracterização da vegetação e uma nova classificação apenas para duas classes de cobertura da terra Vegetação Secundaria e Cerrado, a fim de estimar o índice de vegetação - NDVI. 


\section{Processamento de imagens}

Para a análise das mudanças de uso e cobertura da terra foi realizada a classificação do município de Vigia, foram utilizadas imagens do sensor TM/Landsat 5 para o ano de 1985 e do sensor OLI/Landsat 8 para 2018. As imagens foram obtidas do banco de dados do Landsat no GEE, nível e coleção 1, disponibilizadas com correção geométrica, radiométrica e atmosférica.

Para estimar o Índice de Vegetação por Diferença Normatizada -NDVI, a classificação foi realizada com imagens do sensor Sentinel 2 para o ano 2017 utilizando as bandas 3 (V) e 4 (IVP) do sensor TM/Landsat 5 e as bandas 4 (V) e 5 (IVP) do sensor Sentinel no ano de estudo. Estas imagens foram obtidas do banco de dados do Sentinel 2 no Google Earth Engine, do nível e coleção 1, já disponibilizadas com correção geométrica, radiométrica e atmosférica. Foram selecionadas imagens dos meses de janeiro a Dezembro. Sobre o processamento das imagens foi utilizada a linguagem de programação JavaScript, utilizada no ambiente de programação do GEE, denominada Code Editor, em que todo o processamento é realizado em nuvem. A partir das imagens selecionadas foram realizados os cálculos do índice espectral NDVI, a partir da Equação 1:

$$
N D V I=\frac{(\mathrm{INP}-\mathrm{V})}{(\mathrm{IVP}+\mathrm{V})} \text { Eq. } 1
$$

O NDVI permite identificar a presença de vegetação e caracterizar sua distribuição espacial e sua evolução no decorrer do tempo (ROSEMBACK; FRANÇA; FLORENZANO, 2005; LOBATO et al., 2010). Este índice foi proposto por Rouse et. al., (1973), a partir da normalização do índice de vegetação Razão Simples, variando em um intervalo de -1 a 1, consistindo em uma relação entre as medidas espectrais de duas bandas, a do infravermelho próximo (IVP) e a do vermelho (V).

\section{Classificação de Uso e Cobertura da Terra}

A classificação de uso e cobertura da terra foi realizada através da plataforma do Google Earth Engine - GEE, desenvolvido no modelo Paas, plataforma de serviço que fornece ao usuário um conjunto de ferramentas para desenvolver aplicações para computação em nuvem, implantar e administrar o software, comportando além de uma grande quantidade de usuários, processamento de dados que podem ser acessados de qualquer ponto na internet (Taurion, 2009; Schmitt \& Damasco, 2012).

Na plataforma do GEE é possível realizar análises avançadas, métodos de mistura não espectral, métodos baseados em objetos, análise automática e modelagem linear, além de classificação supervisionada e não supervisionada, utilizando um catálogo de vários dados prontos para análise de dados ambientais em escala planetária, acoplado ao serviço de computação em nuvem paralelo de alto desempenho (Gorelick et al., 2017).

A classificação de uso e cobertura da terra foi adotada e adaptada a partir das classes utilizadas pelo projeto TerraClass que qualifica as áreas desflorestadas em diferentes usos e coberturas. A partir dos resultados gerados pelo TerraClass é possível fazer a avaliação da dinâmica do uso e ocupação dessas áreas, além de oferecer subsídios para ações referentes ao desenvolvimento da produção agrícola nacional com bases sustentáveis à preservação da biodiversidade e manutenção da qualidade dos serviços ambientais (Almeida et al., 2016).

No projeto TerraClass foram definidas 12 classes temáticas de uso e cobertura, agricultura anual, área não observada, área urbana, mineração, mosaico de ocupações, pasto com solo exposto, pasto sujo, pasto limpo, regeneração com pasto, vegetação secundária, outros e desmatamento do ano, além das três classes temáticas do Projeto PRODES, floresta, não floresta e hidrografia. Neste trabalho foram adotadas as classes: Floresta, Vegetação Secundária, Pastagem, Hidrografia, 
Cerrado, Urbano e Outros (abrangendo as classes de nuvem e sombra). A descrição das classes temáticas de uso da terra utilizadas para interpretação dos dados é apresentada no Quadro 1.

Quadro 1. Descrição das classes de uso e cobertura da terra adaptadas do Projeto TerraClass.

\begin{tabular}{|c|l|}
\hline \multicolumn{2}{|c|}{ Descrição das Classes de uso e cobertura da terra } \\
\hline Floresta & $\begin{array}{l}\text { Vegetação arbórea pouco alterada ou sem alteração, com formação de dossel contínuo } \\
\text { que se apresenta fora da máscara do PRODES. }\end{array}$ \\
\hline Vegetação Secundária & $\begin{array}{l}\text { Áreas que, após a supressão total da vegetação florestal, encontram-se em processo } \\
\text { avançado de regeneração da vegetação arbustiva e/ou arbórea ou que foram utilizadas } \\
\text { para a prática de silvicultura ou agricultura permanente com uso de espécies nativas ou } \\
\text { exóticas. }\end{array}$ \\
\hline Pastagem & Áreas de pastagem e áreas agrícolas. \\
\hline Hidrografia & Águas superficiais formadoras de espelhos d’água. \\
\hline Cerrado & $\begin{array}{l}\text { Formação vegetal natural não florestal com características de cerrado, campinas ou } \\
\text { campinaranas em pequenas áreas dentro da máscara de desflorestamento do PRODES. }\end{array}$ \\
\hline Urbano & $\begin{array}{l}\text { Manchas urbanas decorrentes da concentração populacional formadora de lugarejos, } \\
\text { vilas ou cidades. }\end{array}$ \\
\hline Outros & Áreas de nuvens e sombras de nuvens que impedem a visualização das feições em solo. \\
\hline
\end{tabular}

Fonte: Autores.

\section{Caracterização da Vegetação e NDVI}

Para caracterização da vegetação foi realizada uma expedição de campo no dia 07 de novembro de 2018, no município de Vigia, onde foi analisado o uso e cobertura de uma área de transição de Vegetação secundária e Cerrado. Foram adquiridas informações sobre diversos parâmetros relacionados às áreas em questão como: a fitofisionomias da vegetação das duas áreas, o solo, histórico da área e sua importância para a biodiversidade e aspectos do fragmento de vegetação secundária que faz contato com a área de cerrado (Figura 2).

Figura 2. Área de transição de Cerrado e Vegetação secundária no município de Vigia-PA.

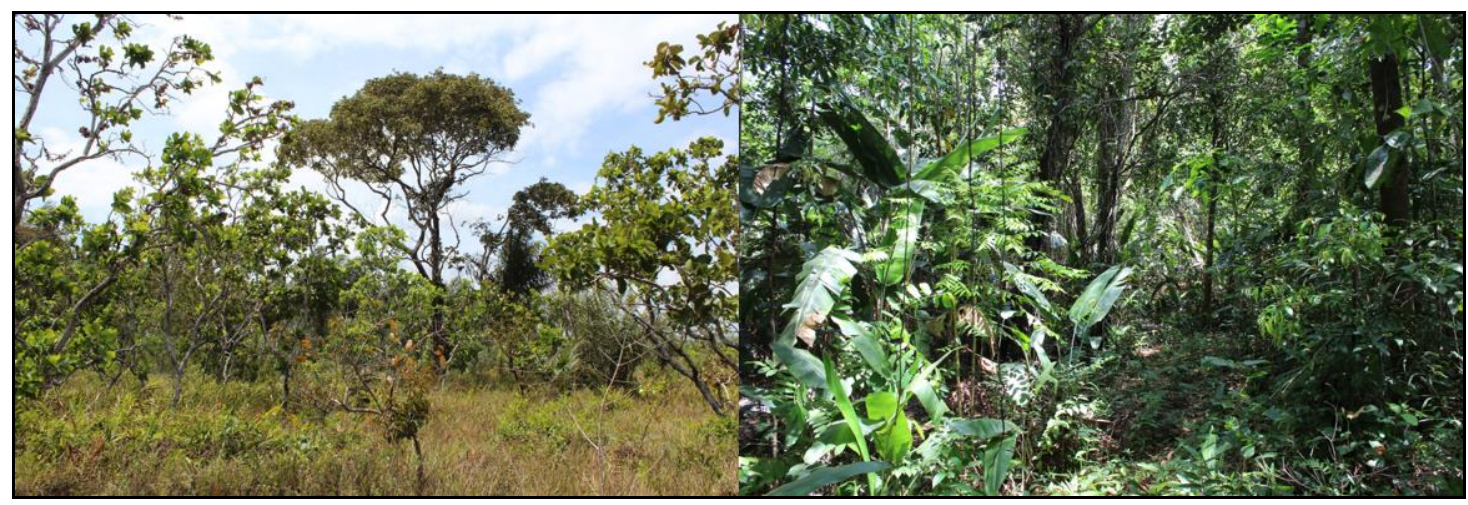

Fonte: Autores.

Na plataforma GEE foi criado o projeto chamado Vigia, onde foram importadas as imagens Sentinel-2 MSI: MultiSpectral Instrument, Level-1C, criadas a variáveis do limite da área de estudo, criado os pontos de treinamento das classes observadas na imagem como VS, cerrado e solo exposto, após classificação foram criados um ponto chamado VS1 na área de vegetação secundária e um polígono chamado cerrado1 para cálculo do NDVI. 


\section{Resultados e Discussão}

Mapeamento do uso e cobertura da terra no município de Vigia-PA

As análises realizadas mostraram alterações no uso e cobertura da terra no município de Vigia-PA nos anos de 1985 e 2018, destacando-se aumento nas seguintes classes temáticas, Outros, Pastagem, Urbano e Vegetação secundária e diminuição nas classes de Cerrado e Floresta. A classe Outros, correspondente as áreas impossibilitadas de serem observadas pelo sensor devido a presença de nuvens ou sombra, a mesma foi de $3,50 \mathrm{~km}^{2}$ para o ano de 1985 , aumentando para $6,36 \mathrm{Km}{ }^{2}$ no ano de 2018.

A classe Pastagem apresentou aumento, passando de $107 \mathrm{~km}^{2}$ em 1985 para $108 \mathrm{Km}^{2} \mathrm{em}$ 2018, perdendo área para as classes Urbano e Vegetação Secundária, $9,85 \mathrm{~km}^{2}$ e $60,43 \mathrm{Km}^{2}$, respectivamente. Vale ressaltar que $6,91 \mathrm{Km}^{2}$ de pastagem foi proveniente da classe Floresta.

A justificativa para o aumento da área pastoril nessa região é que a pecuária por ser uma atividade extensiva no município de Vigia, exige maior área para o plantio, logo a derrubada de florestas é sempre inevitável para atender a esta necessidade. Ação esta que promove o aumento do desmatamento e impactos sobre o solo e a biodiversidade. Diante disso, é importante ressaltar que os processos de mudança da paisagem como o desmatamento, ocorre em um nível mais acelerado que o ciclo natural dos ecossistemas (Romão, et al 2017).

Segundo Rebello et al (2013), destacam que no período de 2000 a 2010 foram contratadas para a Mesorregião Nordeste Paraense 146.969 operações de crédito rural, envolvendo a cifra de R\$1,3 bilhão, ou seja, 17,55\% do valor aplicado no estado do Pará, aspecto este que pode ter contribuído para a manutenção da agropecuária em valores expressivo. Ainda de acordo com os autores, coube ao setor pecuário $\mathrm{R} \$ 577,45$ milhões $(44,61 \%)$ do montante do crédito alocado, aproximadamente, $45 \%$ da quantia destinada no período 2000 a 2010 para a Mesorregião Nordeste Paraense.

O aumento da Classe Urbano, que abrange áreas de Infraestrutura Urbana e Outra área não Vegetada, correspondia a uma cobertura de 9,65 $\mathrm{km}^{2}$ em 1985, chegando a 29,41 $\mathrm{Km}^{2}$ em 2018, representando um aumento na cobertura dessa classe de 19,76 km², ou seja, nos últimos 33 anos a área urbanizada aumentou 7,32 \%. Tal resultado deve-se principalmente ao fato da cidade de Vigia de Nazaré, que tem a pesca como importante segmento da economia local, a partir da década de 80, passa a receber maior fluxo de equipamentos e capitais que intensificam a atividade pesqueira que por sua vez tende a acelerar expressivamente o processo de urbanização da cidade, conseqüentemente impactando na estrutura urbana da cidade de modo geral (Saldanha \& Silva, 2015).

A Classe de Vegetação Secundária apresentou um aumento de 32,92 Km², passando de 161,13 Km² em 1985 para $194,05 \mathrm{Km}^{2}$ em 2018, sendo a principal contribuição da classe de pastagem com 60,43 Km².

Com relação à classe Floresta, observou-se que de 1985 a 2018 o tamanho destas áreas representa uma supressão da floresta com perda de 51,93 km² em 33 anos. Este declínio pode ser decorrente do aumento do desmatamento e conversão de áreas em pastagem e vegetação secundária. No geral, o município de Vigia está inserido dentro da Mesorregião Nordeste Paraense, uma das mais antigas áreas de colonização da Amazônia, caracterizada pela intensa antropização da paisagem, com perda substancial de suas características naturais (Metzger, 2002; Watrin et al., 2009). Conforme informações do SEPOF-PA (2010), devido intensa ação antrópica no município, praticamente já não existe mais áreas de floresta primária. Hoje apenas as áreas de mangues são consideradas áreas naturais, quanto aos tipos de florestas, considerando os diferentes ecossistemas destaca-se: as florestas de várzeas; as mata ciliares; e os manguezais.

A classe de Cerrado apresentou uma diminuição expressiva, no ano de 1985 o município de Vigia apresentava 9,85 $\mathrm{km}^{2}$, diminuindo para $4042 \mathrm{~km}^{2}$ no ano de 2018, perda de 5,42 $\mathrm{Km}^{2}$ de área de Cerrado, perdendo para classes de urbano, pastagem e vegetação secundária. 
Gráfico 1. Distribuição de classes de uso e cobertura do município de Vigia-PA, anos 1985 e 2018.

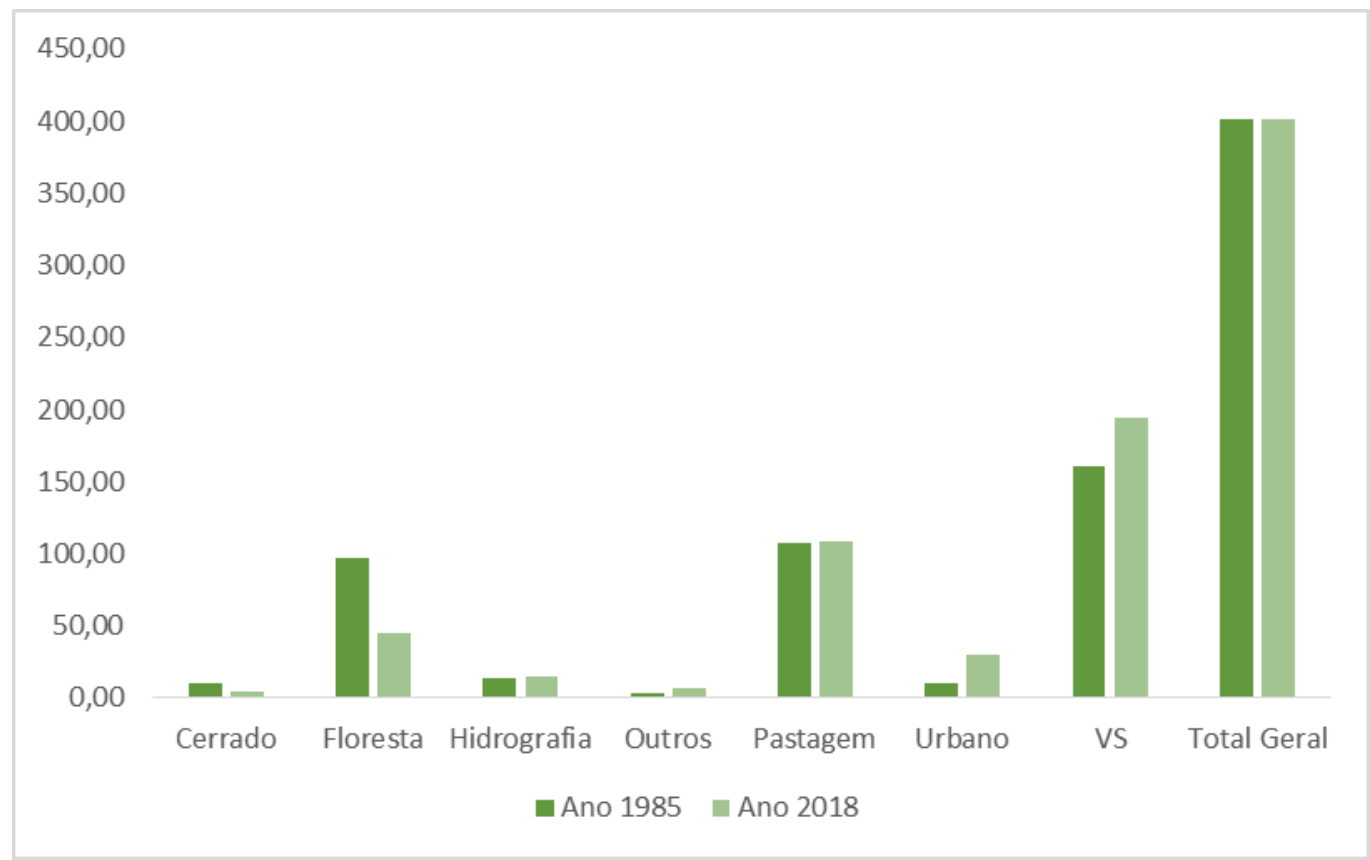

Fonte: Autores.

Os resultados apresentados e discutidos neste trabalho geraram mapas e recortes para o município de Vigia, correspondentes às Figuras 3. Os mapas de classificação confirmam os resultados apresentados anteriormente. No recorte da área ao sul do município, são perceptíveis a dinâmica e o aumento das áreas de classes do uso e ocupação do solo, principalmente na expansão da classe Pastagem sobre as áreas de Floresta. 
Figura 3. Mapa de uso e cobertura do solo para os anos de 1985 e 2018 e das áreas alteradas durante o período analisado para o município de Vigia-PA.

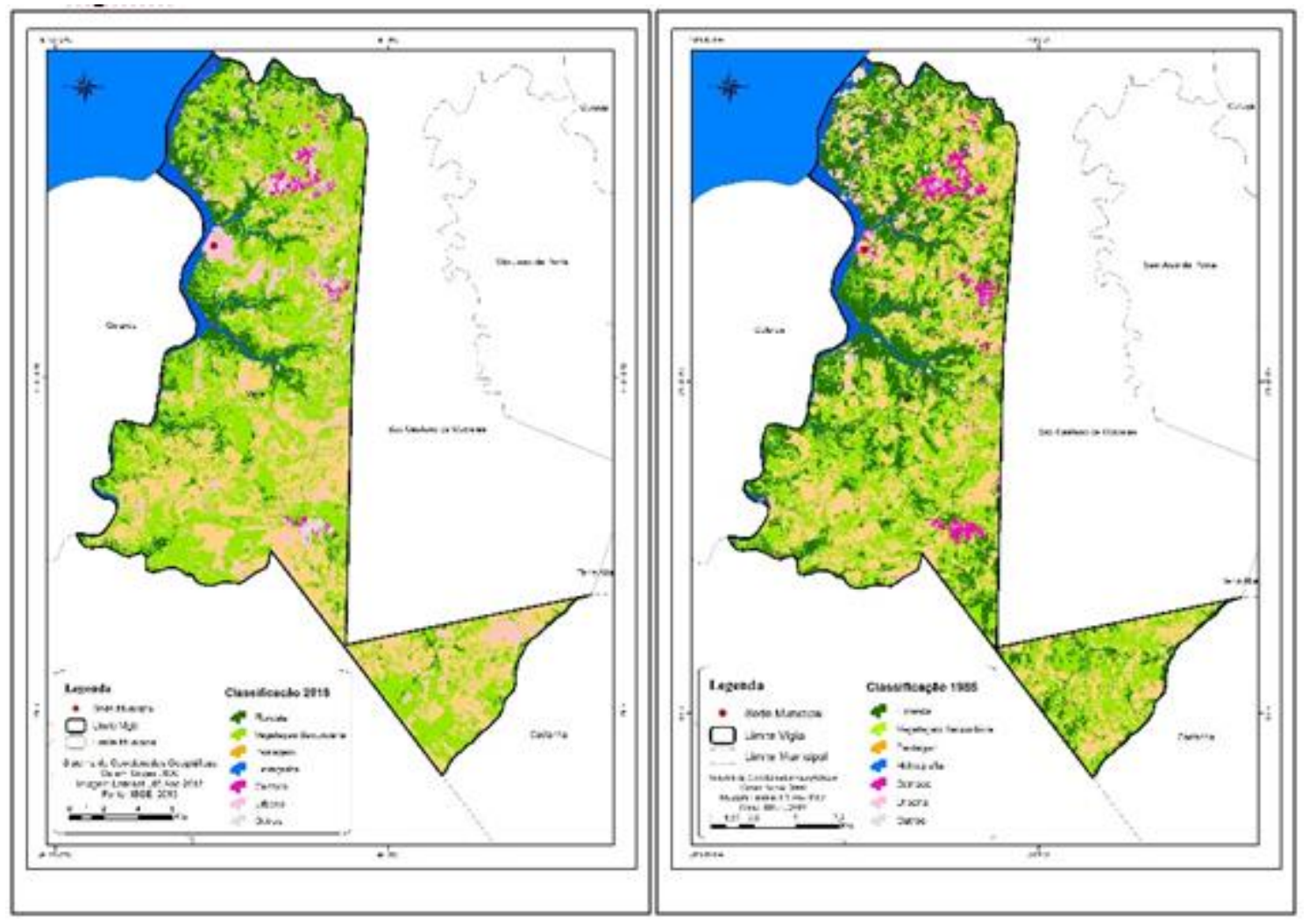

Fonte: Autores.

\section{Caracterização das áreas de Cerrado e Vegetação Secundária}

O primeiro ponto visitado foi a área de Cerrado, foram constatadas formações vegetais abertas com um estrato herbáceo sempre presente, estratos arbustivos e arbóreos mais ou menos desenvolvidos aproximando do conceito de Coutinho (1978) onde retrata que o Cerrado como um todo não é uma vegetação caracterizada por uma única flora, mas no mínimo duas, sendo uma herbáceo-subarbustiva e outra lenhosa, ambas se distribuem por toda a extensão do Cerrado, mas não de forma homogênea.

Observou-se que existe predominância entre 50 e $60 \%$ de duas espécies vulgarmente conhecidas como Muruci, Byrsonima crassifolia, pertencente à família Malpighiaceae, ordem Malpighiales, possui altura média de 6 a 16 m, flores de cachos amarelos, fruto pequeno de $0,8 \mathrm{~cm}$ em cacho, árvore frequente em regiões de cerrado, sendo a espécie de maior extrativismo nesta região. A espécie Curatella americana conhecida popularmente como "lixeira" ou "caimbé" é a segunda mais frequente nesta região de cerrado, do tipo arbustiva da família Dilleniacea, ordem Dilleniales, é uma árvore de porte mediano a alto, de troncos e galhos tortuosos, podendo chegar a 12 metros de altura, suas folhas são ásperas como lixa, grande e coriáceas, além de possuir uma ampla dispersão tropical e ocorrem frequentemente em áreas de savanas, florestas secas e cerrados (Hiruma-Lima, 2009). A espécie de arbusto bastante encontrada foi o Alecrim do campo (Baccharis dracunculifolia) e a espécie de herbácea predominante foi o capim mimoso (Axonopus marginatus). Também outras espécies de características de cerrados foram observadas como o Murici (Byrsonima crassifólia (L.) Rich) e a palmeira Babaçu (Attalea ssp).

Notou-se ao redor da área de cerrado um fragmento de vegetação secundária de aproximadamente 35 anos de idade, com indivíduos arbóreos medindo aproximadamente 15 metros de altura no estrato mais alto e espécies que caracteriza uma floresta secundaria (Figura 4) como o morototó, Schefflera morototono (Aubl.), o Ingá vermelho (Ingá alba) e a palmeira 
bacaba (Oenocarpus bacaba). Outra espécie bem frequente na área de vegetação secundaria foi a bananeira brava (Heliconia rostrata), esta espécie apresenta ocorrência em área sombreada com solo rico em matéria orgânica, irrigado com frequência, vale ressaltar que, na área onde foi encontrada a ocorrência de bananeira, constatou-se um curso de rio intermitente que na estação chuvosa enche chegando aproximadamente à altura de 1,5 m, formando um ambiente propício para a ocorrência dessa espécie.

Figura 4. Cerrado e Floresta secundária.

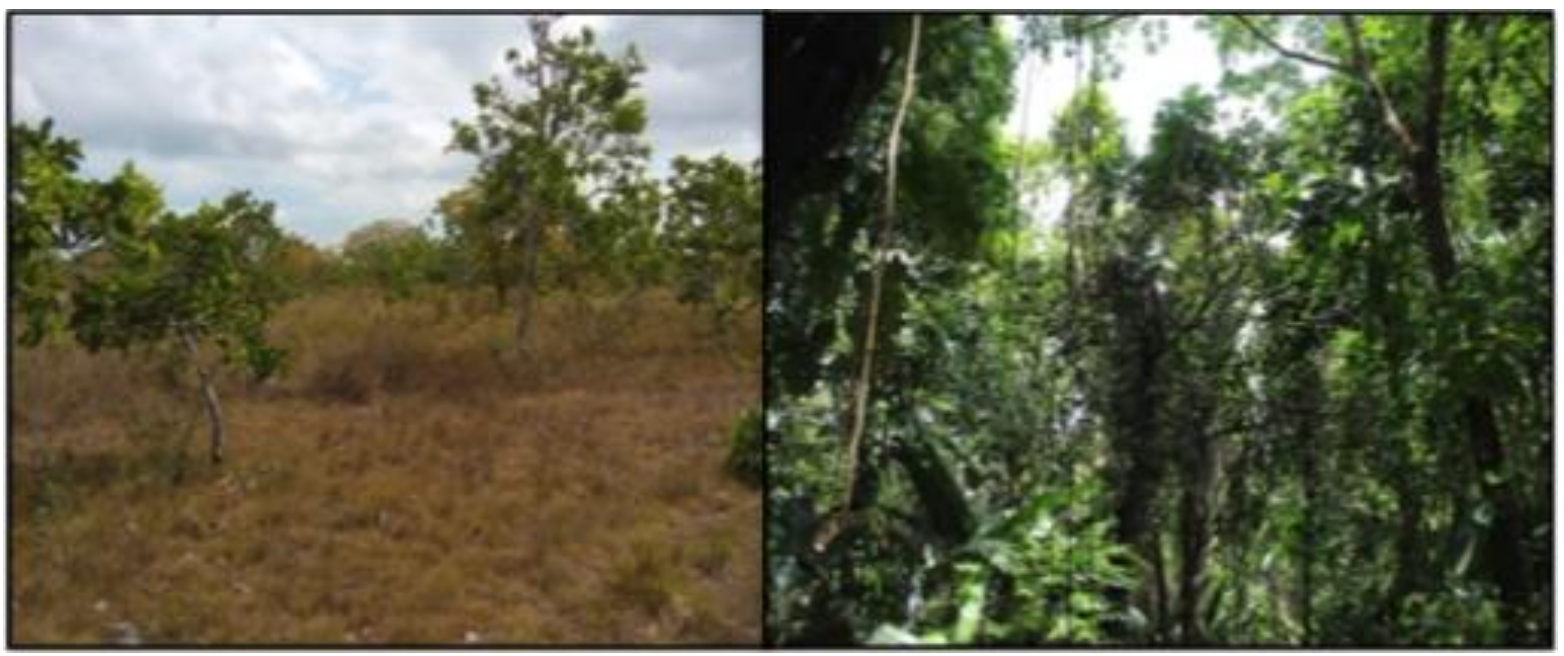

Fonte: Autores.

Foi observado também a presença da palmeira Mauritiella armata, conhecida como Caranã, característica de áreas de igapó, margens de rio e igarapés, servem como refúgio da fauna silvestre e são importantes fontes de águas naturais de terra firme, conservando os locais alagados com água saudável e permanente. Apresenta muitos acúleos cônicos na estirpe, medindo de 2 a $3 \mathrm{~cm}$ na posição vertical, a palmeira pode chegar a medir até $20 \mathrm{~m}$ de altura e cerca de $30 \mathrm{~cm}$ de diâmetro.

A espécie popularmente conhecida como Marajá, uma palmeira de aproximadamente $6 \mathrm{~m}$ de altura, com caule e folhas cobertos por espinhos, seu fruto é utilizado para fazer licor e as sementes como adornos de brincos e colares.

Nesta área observou-se também a presença da espécie Symphonia globulifera L. conhecida popularmente como Ananim, pertencente à família Clusiaceae, árvore que pode chegar à altura de $40 \mathrm{~m}$, com preferência por terrenos alagadiços, possui madeira de cor castanha, pesada dura e de aproveitamento econômico, seu tronco libera uma espécie de látex de cor amarelo intenso.

Notou-se também a ocorrência de espécies da família Fabaceae, abrangendo espécies de árvore e herbáceas, possui característica importante de simbiose de suas raízes com as bactérias do gênero Rhizobium que fixam nitrogênio da atmosfera e convertem o gás nitrogênio em nitrato ou amônia, melhorando a qualidade do solo, auxiliando para a recuperação de áreas degradadas.

Após caracterização "in loco" das duas áreas e coleta de coordenadas geográficas, foi possível classificar a área amostral e estimar o NDVI na plataforma do GEE.

\section{Estimação do Índice de Vegetação - NDVI}

Foi realizada a classificação da área amostral, tendo como resultado três classes de uso e cobertura, cerrado, vegetação secundária e solo exposto. Nesta amostragem observou-se que a maior classe foi de cerrado e ao redor um pequeno fragmento 
de vegetação secundária que está sendo desflorestada às suas proximidades, resultando à classe de solo exposto, bem expressiva (Figura 5).

Figura 5. Amostragem das classes na imagem para classificação de NDVI.

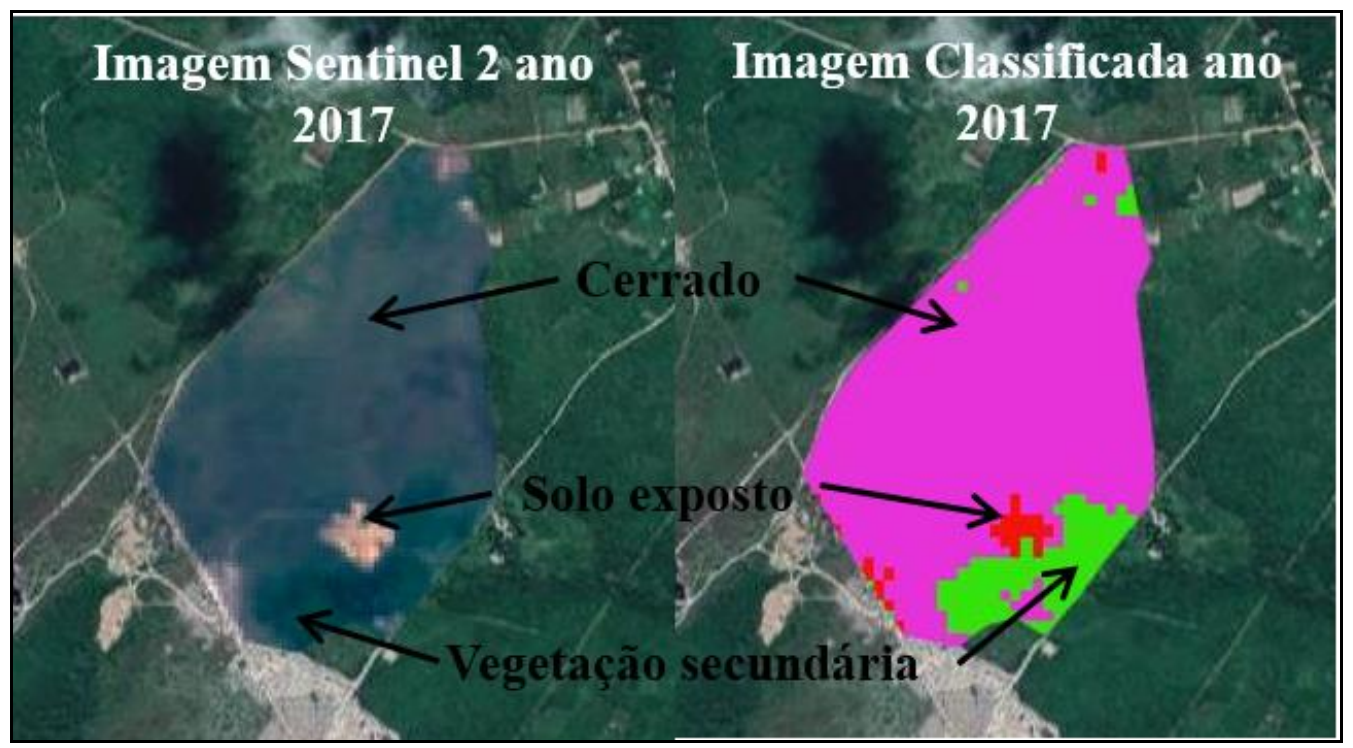

Fonte: Autores.

Após classificação foi realizada a análise do NDVI para as áreas de cerrado (polígono em azul) e vegetação secundária (polígono em verde), a fim de avaliar a condição geral dos tipos de vegetação (Figura 6).

A partir de agosto de 2017 o NDVI apresentava valor de 0,6 no cerrado, diminuindo gradativamente para 0,5 até outubro de 2017, ou seja, se aproximando de ausência de vegetação. Já para floresta secundária o NDVI se apresentou com valor um pouco maior do que no cerrado em agosto de 2017, de 0,8 , mais próximo de 1 indicando que ainda havia vegetação fotossinteticamente ativa neste período, porém no decorrer da análise esse valor tende a diminuir gradativamente para 0,6 em setembro de 2017, chegando a 0,5 em outubro de 2017, mostrando que está ocorrendo a perda de vegetação secundária, o que foi possível visualizar in loco com a degradação e desmatamento deste fragmento (Figura 6).

Figura 6. Estimativas de NDVI para duas classes no Município de Vigia -PA: A) Cerrado, B) Vegetação Secundária.

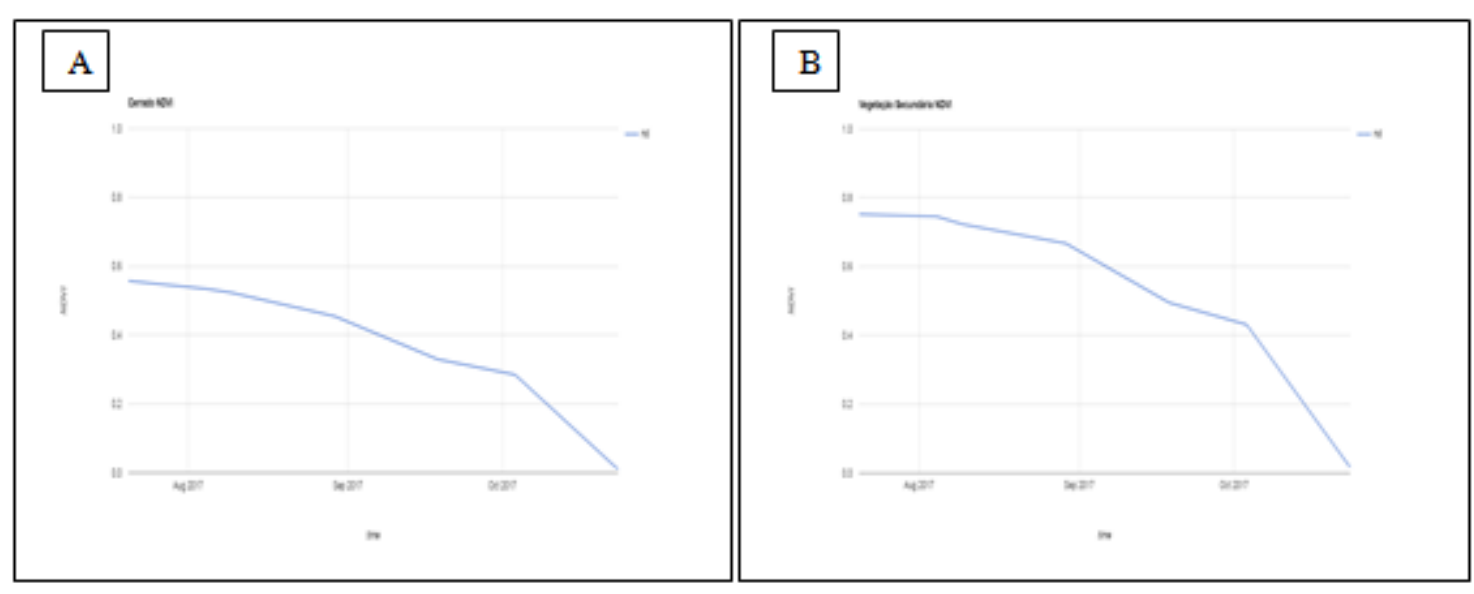

Fonte: Autores. 
Percebe-se que os maiores valores de NDVI foram registrados na fitofisionomia de área de vegetação secundária em relação ao cerrado, pois se trata de dois tipos de formação de vegetação diferentes e apresentam estruturas verticais e horizontais diferentes. Isso pode ser atribuído à estrutura radicular desenvolvida dessas formações, em comparação à de cerrado (Nepstad et al., 1994) assim como muitas espécies de arbustos perdem as folhas, comportamento típico do bioma cerrado, resultando em menores valores de NDVI (Pavão et al., 2015).

Para o mês de agosto as duas classes apresentaram índices de vegetações semelhante aos índices nas mesmas classes no estudo de Gamarra et al. (2015) onde estimou o NDVI também em período seco em três áreas de mata secundária e 7 áreas de cerrado. Para o cerrado foram obtidos valores que variavam entre 0,7 a 0,9 para mata secundária e 0,5 a 0,7 para o cerrado no Mato grosso do Sul.

Diante do mapeamento é possível entender o padrão espacial do uso e cobertura da terra através do sensoriamento remoto que auxilia nos estudos de biodiversidade, modelagem ambiental e mudanças climáticas, essencial para a criação e acompanhamento de políticas do uso da terra (Almeida et al., 2016).

\section{Conclusão}

O monitoramento de uso e cobertura das da terra torna-se importante para as áreas consideradas de não floresta como o Cerrado, principalmente no bioma Amazônia, pelas características peculiares de transição entre Cerrado e outros tipos de vegetação, pois com o monitoramento é possível detectar degradações e desmatamento, contribuindo dessa forma para a gestão de políticas públicas voltadas para a preservação da biodiversidade dessas áreas.

\section{Referências}

Abreu, K. M. P, \& Coutinho, L. M. (2014). Sensoriamento remoto aplicado ao estudo da vegetação com ênfase em índice de vegetação e métricas da paisagem. Vértices, 16(1), 173-198.

Almeida, C. A., Coutinho, A. C., Esquerdo, J. C. D. M., Adami, M., Venturieri, A.,Diniz, C. G., Dessay, N., Durieux, L., \& Gomes, A. R. (2016). High spatial resolution land use and land cover mapping of the Brazilian Legal Amazon in 2008 using Landsat-5/TM and MODIS data. Acta Amazonica, Manaus, 46(3), $291-302$.

Begon, M., Townsend, C. R. \& Harper, J. L. (2007). Ecologia de Indivíduos a Ecossistemas. (4a ed,), Artmed, Blackwell.

Ferreira, J., Pardini, R., Metzger, Jp., Fonseca, C., Pompeu, P., Sparovek, G., \& Louzada, J. (2012). Towards environmentally sustainable agriculture in Brazil: challenges and opportunities for applied ecological research. Journal of Applied Ecology, 49 (3), 535541.

Gardner, Toby A., et al. (2013). A social and ecological assessment of tropical land uses at multiple scales: the Sustainable amazon network. Philosophical Transactions of the Royal Society B: Biological Sciences, 368 (1619). 20120166.

Google Earth Engine. (2018). https://developers.google.com/earth-engine/

IDESP. (2012). Instituto de desenvolvimento econômico, social e ambiental do Pará. http://seicom.pa.gov.br/kitmineracao/estatistica-municipal/regiao-doguama/Vigia.pdf.

Instituto Brasileiro De Geografia E Estatística - IBGE. (2010). https://cidades.ibge.gov.br/brasil/pa/vigia/panorama.

Instituto Brasileiro De Geografia E Estatística - IBGE. (2012). Manual técnico da vegetação brasileira. Rio de Janeiro.

Instituto Nacional De Pesquisas Espaciais - INPE. (2017). Monitoramento da Floresta Amazônica Brasileira por Satélite. 2017. http://www.obt.inpe.br/prodes/dashboard/prodes-rates.html.

Magurran, A. E. (2011). Medindo a Diversidade Biológica. Curitiba: UFPR.

Miura, T., Huete, A. R., Yoshioka, H., \& Holben, B. N. (2001). An error and sensitivity analysis of atmospheric resistant vegetation indices derived from dark target-based atmospheric correction. Remote Sensing of Environment, 78, 284- 298.

PBMC. (2016). Impacto, vulnerabilidade e adaptação das cidades costeiras brasileiras às mudanças climáticas: Relatório Especial do Painel Brasileiro de Mudanças Climáticas. PBMC, COPPE - UFRJ. 184 p.

Ponzoni, F. J., \& Shimabukuro Y. E. (2009). Sensoriamento Remoto no estudo da vegetação. A. Silva Vieira Ed. 127p.

Primack, R., \& Rodrigues, E. (2001). Biologia da Conservação. E. Rodrigues. 
Research, Society and Development, v. 11, n. 3, e7411325804, 2022

(CC BY 4.0) | ISSN 2525-3409 | DOI: http://dx.doi.org/10.33448/rsd-v11i3.25804

Ramos C. A. R. (2007). Qualidade ambiental, distribuição e densidade do mesozooplâncton do estuário de guajará-miri, Vigia de Nazaré, NE do estado do Pará. 2007. 126 f. Dissertação (Mestrado em Ciência animal) - Universidade federal do Pará, Belém.

Ricklefs, R. E. (2011). A Economia da Natureza. (5a ed.), Editora Guanabara Koogan.

SEPOF. (2017). Secretaria de Planejamento, Orçamento e Finanças - PA.

SEPOF-PA. (2010). Secretaria de Estado de Planejamento, Orçamentos e finanças. Estatística Municipal: Vigia. Pará. http://iah.iec.pa.gov.br/iah/fulltext/georeferenciamento/vigia.pdf.

Silva, A. C. (2018). Comportamento de paricá (Schizolobium parahyba var. amazonicum (Huber ex Ducke) Barneby) em diferentes condições edafoclimáticas influenciado por níveis contrastantes de fertilização do solo. Trabalho de Conclusão de Curso, Universidade do Estado do Pará - Campus VI, Paragominas.

Vieira, I. C. G., \& Gardner, T. A. (2012). Florestas secundárias tropicais: ecologia e importância em paisagens antrópicas. Boletim do Museu Paraense Emílio Goeldi. Ciências Naturais. 7(3), 191-194. 